\section{Seasonal Allergy Induced Back Pain: A Report of Two Cases}

\author{
Sue Killian ${ }^{1 *}$ and John McMichael ${ }^{1,2}$ \\ ${ }^{1}$ The Institute for Therapeutic Discovery, Westfall Road, Delanson, NY, \\ USA \\ ${ }^{2}$ Beech Tree Laboratories, Chapman Street, Providence, RI, USA
}

\begin{abstract}
Introduction: Throughout the past few decades, physicians have observed the co-occurrence of back pain and allergic conditions. A review of the chemicals involved in the allergic cascade may help to explain this association.

Cases: These case studies illustrate a co-occurrence of seasonal allergies and back pain for which there is no obvious cause. Two patient cases were tested and treated using the provocationneutralization (PN) method of allergy treatment and experienced pain relief using this method.

Discussion: The allergic cascade produces inflammatory, pain-producing cytokines and neuropeptides which may exacerbate other chronic conditions.

Conclusion: By controlling the allergic response through appropriate immunotherapy, co-occurring back pain often diminishes.
\end{abstract}

\section{Introduction}

A computerized literature search using PubMed (www.nlm.nih. gov) documented other physicians' observations of the co-occurrence of back pain and allergy. As early as the 1920's, Dr. AH Rowe demonstrated that chronic muscular pain often had a food allergy connection [1,2]. More than fifty years ago, Dr. WN Sisk, an industrial medicine physician with the Upjohn Company in Michigan, wrote that many allergy patients "suffer from spastic myalgia" manifesting as sudden, intense pain or "generalized aches and pains" in cases where there was no apparent injury to account for the symptoms. A nurse he employed experienced neck pain and headache whenever she ate chicken [3].

Theron Randolph, described the co-occurrence of allergy and muscle spasms in a patient whose family harbored an apple allergy. In

*Corresponding author: Sue Killian, The Institute for Therapeutic Discovery, Westfall Road, Delanson, NY, USA, Tel: +1 5188721144; E-mail: skillian@shentel.net

Citation: Killian S, McMichael J (2015) Seasonal Allergy Induced Back Pain: A Report of Two Cases. J Allergy Disord Ther 2: 005.

Received: March 25, 2015; Accepted: August 25, 2015; Published: September 10, 2015 a 1976 publication, Randolph pleaded for physicians to consider the connection between allergy and myalgia. "The most important point in making a tentative working diagnosis of allergic myalgia is to think of it. The fact remains that this possibility is rarely ever considered and is even more rarely approached by means of diagnostico-therapeutic measures capable of identifying and avoiding the most common environmental incitants and perpetuants of this condition namely, specific foods addictants, environmental chemical exposures and house dust" [4].

Dr. AH Rinkel and colleagues listed symptoms of allergy as "low back pain, muscle tightness and muscles pulling" with discomfort in nuchal and hamstring muscles with the sharp pain often resembling that of sciatica [5]. Allergist Joseph Miller wrote, "Physicians interested in food allergy are very familiar with the ability of foods to cause muscle spasms and joint pain in various parts of the body. We frequently see food-allergic patients suffering from muscle and joint pains of the chest, back, abdomen, arms, legs or the back of the neck" [6].

Epidemiologists Hurwitz and Morgenstern interviewed a large population between 20 and 39 years of age and found that patients with a history of allergy were $50 \%$ more likely to report suffering from back pain and depression [7]. More recently, a 2009 study in the Journal of Pain concluded that women with incontinence or allergy were at a greater risk for developing back pain than women without those conditions. They suggested that back pain in allergic individuals was a result of changes in the trunk muscles and the muscles of respiration (diaphragm and transverses abdominis) resulting in "compromised postural control". They also noted that sneezing and coughing are associated with trunk muscle co-contraction and "increased spinal loading" adding to the "development of pain" [8].

\section{Cases}

The Medical Director of the Center for Occupational and Environmental Medicine (COEM), in N. Charleston, SC, told of his observations that some patients routinely arrive at his practice for allergy treatment with coincidental back pain. This clinic has an integrative approach to allergy treatment using provocation neutralization immunotherapy as well as traditional allopathic strategies to interrupt disease processes and restore homeostasis. Physicians at the COEM have observed that the need for both the relief of allergy symptoms and relief of back pain occurs during high levels of atmospheric pollen. The use of pollen antigens to control the allergic response was anticipated, but the simultaneous diminishing of the back pain was unexpected.

Physicians observed that allergy and muscle pain were not only related but that muscle and joint symptoms could be diminished by successfully treating allergies $[3,6]$. The purpose of this paper is to report two cases of allergy and back pain and to discuss how allergy desensitization using the method of provocation neutralization $(\mathrm{PN})$ of allergy testing and treatment might impact that pain.

An explanation of the PN method is a prerequisite to the unexpected immediate response found observed in these two case 
studies. Provocation-neutralization allergy testing and treatment is a method developed in 1957 by Carleton H Lee [4] which refines intradermal skin testing [6] to determine the level which will relieve the patients reactivity to a particular allergen while being tested.

Each concentrate of antigen is diluted into 9 or more vials $(9$ serial dilutions). Each elevation in number is a five-fold dilution (a $5 \mathrm{x}$ dilution) therefore the most concentrated is a \#1, and \#2 is $5 x$ more dilute than \# 1 etc. The highest number is the greatest dilution.

As with traditional allergy testing, a positive wheal indicates a localized allergic reaction. Different dilutions of the same antigen are injected intradermally to produce a wheal, but the neutralizing dilution will produce a negative wheal. The strongest negative wheal produced is associated with the proper dilution of antigen, the neutralizing level, which is used to create the patients individualized therapeutic formulation.

The patient may be neutralized to ragweed at level 5 , to oak pollen at level 6 and to a particular mold at level 4 . The specific level of each antigen is used to create a custom-made, unique vial of antigens which can be administered as injections or sublingual drops. In addition to the long term effect expected to occur with traditional immunotherapy, there is a yet scientifically unexplained symptom relief in 30 minutes to 2 hours.

\section{Case study 1}

A 45-year-old male physician complained of intermittent chronic neck and back pain and said that he would generally just "grin and bear it". He was finally persuaded to seek chiropractic care which gave him some temporary relief.

At a visit to his chiropractor, he was asked if he realized that this was the fourth time he had sought help and each of these visits occurred in February. The cyclical and apparent seasonal occurrence made him wonder if his neck and back pain were triggered by tree pollen.

He underwent provocative or challenge testing with mountain cedar tree pollen, a predominant pollen in his geographical area from early December to February. A few minutes after cedar pollen antigen was injected, this physician noted relief from his chronic neck and back pain. This quick response of allergy relief is often observed when $\mathrm{PN}$ is used for testing and treatment. Taking the specific dilution of mountain cedar twice weekly completely relieved his seasonal pain.

Of interest, this patient's history revealed that as a college student and episodically during his early years in the navy he had acute onset of severe back pain, so severe he had difficulty even taking a deep breath. Treatment for these attacks was with analgesics and trigger point injections. In retrospect the patient remembered that these acute muscular skeletal episodes were always in the spring.

\section{Case study 2}

A 49 year old woman presented initially at age 42 with multiple complaints including classical atopy manifesting as allergic rhinitis, sinusitis and anaphylaxis to yellow jacket wasps. Signs and symptoms were seasonal, especially spring and fall. When she was 38 years old she injured her back, necessitating surgery for disc compression at L5-S1. After successful surgery she had intermittent, unexplained, disabling back pain.

The patient underwent comprehensive allergy testing and was found to be sensitive to trees, grasses, weeds, dusts and molds. Testing individually with these allergens provoked symptoms of rhinitis but during testing for grasses she exacerbated overt pain in the area of her reported intermittent back aches attacks. Since beginning tree, grass, weed, dust and mold allergy extract treatment, she has demonstrated much improvement and also recognizes a relationship between exacerbation of back pain in grass pollinating seasons if she stops taking her allergy extracts.

This case demonstrates the principle of the previously injured organ or tissue becoming the target of the allergic response. (Personal communication. Allan D Lieberman, MD, COEM).

\section{Discussion}

The effects of an allergic response are often unrecognized by both physicians and their patients. Exposure to an allergen initiates a process involving a complex interaction of twenty or more chemicals. Allergens cause mediators to be released which amplify their damaging effects by initiating other immune processes [6]. This ripple effect is usually referred to as the allergic cascade, and the chemicals involved shed light on allergy's connection to back pain.

The allergic cascade begins with either mast cells or basophils, each having receptors for the antibody usually associated with allergy, $\mathrm{IgE}$, and both cell types store mediators which will be involved in the allergic cascade [9].

The cascade begins with two Y - shaped antibodies, their Y - base sitting on the edge of a single mast cell. The arms of the two adjacent Y's must be connected by an allergen for cascade initiation. This is described in immunology texts as two IgE antibodies becoming cross-linked, inducing degranulation and releasing mediators which cause the allergic reaction [10].

The mediators in allergy can be divided into early response mediators (Table 1) and late response mediators (Tables 2 and 3). Reviewing these tables underscores the complexity of the allergic reaction and belies the notion that the condition is "just allergy" and not a major concern.

\begin{tabular}{|c|l|}
\hline Mediators & \multicolumn{1}{|c|}{ Function } \\
\hline Histamine & Increased vascular permeability; smooth muscle contraction \\
\hline Serotonin & Increased vascular permeability; smooth muscle contraction \\
\hline ECF-A & Eosinophil chemotaxis factor-A. Leukocyte migration \\
\hline NCF-A & Neutrophil chemotactic factor. Neutrophil chemotaxis \\
\hline Proteases & $\begin{array}{l}\text { Degranulation of blood-vessel basement membrane; generation of } \\
\text { complement split products }\end{array}$ \\
\hline Heparin & Anticoagulant \\
\hline
\end{tabular}

Table1: Early response mediators.

Early response mediators are produced before degranulation of mast cells of basophils and are stored in the granules [11].

One can easily visualize Dr. Joseph Miller's simplification of the allergic process. He describes capillaries as a one - cell thick jigsaw puzzle of cells forming tubes with mast cells clinging to the outer sides of the tubes. When an allergen is introduced, each mast cell can "sting" its adjacent capillary cell. Chemical mediators from the mast cell force the local capillary cells to separate slightly, leaking both mediators and antigens into the blood stream. These newly formed gaps between the capillary cells now allow serum to leak into other tissues. The mediators can then cause symptoms by stimulating sensitive stress organs such as the brain, lungs, stomach, colon or the complex association of tissues in the lower back [6]. 


\begin{tabular}{|c|l|}
\hline Mediators & \multicolumn{1}{c|}{ Function } \\
\hline PAF & $\begin{array}{l}\text { Platelet activating factor affects platelet aggregation and degranu- } \\
\text { lation; contraction of pulmonary smooth muscles. }\end{array}$ \\
\hline SRS-A & $\begin{array}{l}\text { Leukotrienes. Slow-reacting substance of anaphylaxis affects } \\
\text { vasodilation; contraction of pulmonary smooth muscles; platelet } \\
\text { aggregation. }\end{array}$ \\
\hline Prostaglandins & $\begin{array}{l}\text { Vasodilation; contraction of pulmonary smooth muscles; platelet } \\
\text { aggregation. }\end{array}$ \\
\hline Bradykinin & Increased vascular permeability; smooth muscle contraction. \\
\hline \multicolumn{2}{|c|}{ Table 2: Delayed response mediators. } \\
Late response mediators are produced after degranulation of mast cells or \\
basophils [11].
\end{tabular}

\begin{tabular}{|c|l|}
\hline Mediators & \multicolumn{1}{c|}{ Function } \\
\hline TNF- $\alpha$ & $\begin{array}{l}\text { A cytokine whose action is initiated hours after the allergic insult. } \\
\text { Activates macrophages, granulocytes, cytotoxic cells, and leukocytes } \\
{[10] .}\end{array}$ \\
\hline IL-1 & $\begin{array}{l}\text { A cytokine released by mast cells. Principal targets: T-cells, B-cells, } \\
\text { macrophages, endothelium, tissue cells [7,10]. }\end{array}$ \\
\hline IL-6 & $\begin{array}{l}\text { A cytokine released by mast cells. Secreted by TH cells TH2 subset, } \\
\text { macrophages, } \\
\text { monocytes, fibroblasts and endothelial cells. Increases secretion } \\
\text { of antibodies by plasmacells, togetherwithIL-1co-stimulates T-cell } \\
\text { activation [11]. }\end{array}$ \\
\hline SP & $\begin{array}{l}\text { Substance P. A pain-producing neuropeptide produced by nerve cells } \\
\text { [12]. }\end{array}$ \\
\hline
\end{tabular}

Table 3: Mediators which may coordinate allergy and back pain.

\section{Allergy and the nervous system}

The central nervous system involves both the brain and spinal cord, which in turn give rise to motor and sensory nerves. Sensory nerves are stimulated by the allergic reaction. Cross linking IgE, leads to IgE triggered mast cell degranulation by an IgE antibody reaction, and can activate other mast cells remote from the site of the allergen exposure. This triggering occurs through the sensory neural system via the release of neuropeptides [13].

The nervous and immune systems are coordinated so that dysregulation of one may affect the other. Some neuropeptides involved in this coordination are the neurotransmitters acetylcholine, serotonin, and substance $\mathrm{P}$ [14].

\section{Immune-neuro-endocrine interactions}

Mediators of immune-neuro-endocrine interactions are Interleukin-1 (IL-1), Tumor Necrosis Factor-alpha (TNF- $\alpha$ ), Interleukin-6 (IL-6) (Table 3) and prostaglandins (Table 2), all of which are involved in the allergic cascade.

IL-1 is an inflammatory cytokines excreted in plasma and tissue fluids. It increases the production of substance $\mathrm{P}$, a pain sensitivity mediator released from the terminals of some sensory nerves (Table 3) [15]. Substance P not only amplifies nerve pain signals [16] but also induces histamine release from mast cells [14], muscles and joints [17]. In addition it increases the production of TNF- $\alpha$, which in association with substance $\mathrm{P}$ activates immune monocytes and macrophages [12].

IL-1 is associated with interactions in the Hypothalamic Pituitary Adrenal axis (HPA axis). The hypothalamus has the role to connect the nervous system and the endocrine system via the pituitary gland. Allergy sufferers secrete pro-inflammatory cytokines, including IL-1, in greater quantities than non-allergic patients. IL-1 activates the HPA axis, "firing the immune response" [7].
The mast cells involved in allergy contain preformed TNF- $\alpha$ granules [11]. After tissue injury occurs, TNF- $\alpha$, which is the primary inflammatory mediator in nerve injury, is also released by macrophages and nerve cells. This TNF- $\alpha$ release increases inflammation and prostaglandin formation which in turn increases the release of the neurotransmitter glutamate, enhancing nerve communication and pain [12].

IL-6 is synthesized in response to IL-1 and TNF- $\alpha$ [15] and acts at the site of inflammation by sensitizing afferent fibers and stimulating their release of prostaglandins [18]. IL-6 is the primary chemical mediator involved in bone inflammation and pain [12].

Prostaglandins are inflammatory mediators which are released both during the allergic cascade and more generally by any inflammatory response, sensitize peripheral nociceptor terminals and generate local pain. Tissues adjacent to inflamed tissues may also become painful due to increased sensitization in the spinal cord $[12,19]$.

\section{The back as a target organ of allergy}

Many unmyelinated nerve terminals are embedded in the interstitial sheaths of the intramuscular blood vessels in the lumbar system. The muscular nociceptive system is perivascular and involves both arteries and veins. These nociceptive receptors are irritated by either mechanical or chemical stimuli to the tissues in which they are embedded. If a chemical, such as histamine, achieves a critical concentration, it can irritate the nociceptive receptor system resulting in lower back pain [20].

Biochemical mediators are both cytokines and neuropeptides. Bradykinin, serotonin, histamine, acetylcholine, prostaglandins, and leukotrienes produced by the immune cells [21,22] as well as substance $\mathrm{P}$ produced by nerve cells [12], cause inflammation which in turn causes pain. While research has focused on single mediators such as a prostaglandin, Dr. Omoigui states the need to address instead the "inflammatory soup of biochemical mediators" that are present in all pain conditions, including back pain. After the inflammatory mediators are released they affect motor nerves that travel from the spinal cord to the muscles and can cause muscle tension, spasm and pain. Inhibition or suppression of the production of inflammatory mediators suppresses motor transmission. The result of less inflammation is less pain [16].

\section{Stopping the pain}

According to epidemiologists Hurwitz and Morgenstern, "two of the most common conditions among patients in primary care, low back pain and depression, maybe caused, in part, by the delayed effects of cytokines released during allergic or other inflammatory reactions" [7], Wilfrid Sisk, MD observed that muscular disturbances responded to the same treatment which brought about are mission of allergies [3]. Patients treated for allergies by provocation-neutralization immunotherapy have often noticed improvement in their muscle and joint pain [6]. This is often observed because of the unexplained immediate effect of PN therapy but the long term effect of both $\mathrm{PN}$ and traditional immunotherapy may maintain this relief.

\section{Conclusion}

While obvious injuries are readily diagnosed, finding and treating non-specific back pain is more challenging. Investigating the 
connections between allergy and back pain reveal that the allergic cascade produces some of the same inflammatory cytokines and neuropeptides which produce back pain. If allergies are concurrent with back pain, treating allergies often has a positive effect on back pain because controlling the allergic cascade diminishes the addition of chemicals common to both conditions.

\section{Acknowledgements}

We would like to acknowledge the assistance of Allan D Lieberman MD of the Center for Occupational and Environmental Medicine, $\mathrm{N}$. Charleston, SC for providing clinical observations and case histories, and Megan Khamphavong, Sentara RMH Medical Center for assistance with library research.

Written consent for publication was obtained from the patients or their relatives. Funding was provided by The Institute for Therapeutic Discovery, www.tiftd.org

\section{References}

1. Rowe A (1930) Allergic toxemia and migraine due to food allergy. Cal West Med 33: 785-793.

2. Albert H Rowe, Albert Rowe (1972) Food allergy: Its manifestations and control and the elimination diets - A compendium. Charles C Thomas, Springfield, Illinois, USA. Pg no: 687.

3. Sisk WN (1954) The part allergy plays in back pain. Ind Med Surg 23: 270272.

4. Randolph T (1976) Stimulatory withdrawal and the alterations of allergic manifestations. In: Dickey L (ed.). Clinical Ecology. Charles C Thomas publisher Itd, Springfield, IL, USA. Pg no: 156-175.

5. Rinkel HJ, Randolph TG and Zeller M (1951) Food Allergy. Charles C Thomas Publisher Itd, Springfield, IL, USA.

6. Miller JB (1987) Relief at Last!: Neutralization for Food Allergy and Other Illnesses. Charles C Thomas Publishers Itd, Springfield, IL, USA.

7. Hurwitz EL, Morgenstern H (1999) Cross-sectional associations of asthma, hay fever, and other allergies with major depression and low-back pain among adults aged 20-39 years in the United States. Am J Epidemiol 150: 1107-1116.

8. Smith MD, Russell A, Hodges PW (2009) Do incontinence, breathing difficulties, and gastrointestinal symptoms increase the risk of future back pain? J Pain 10: 876-886.
9. Cruse JM, Lewis RE (1998) Atlas of Immunology 2nd edn. CRC Press, Boca Raton, USA.

10. Platts-Mills TAE (2006) Immediate Hypersensitivity (Type1). In: Male D, Brostoff J, Roth DB, Roitt I (eds.). Immunology (7thedn). Mosby Elsevier, Edinburg, UK. Pg no: 423-446.

11. Kuby J (1992) Hypersensitive Reactions. In: Kuby J (ed.). Immunology. WH Freeman and Company, New York, USA. Pg no: 357-381.

12. Omoigui S (2007) The biochemical origin of pain--proposing a new law of pain: the origin of all pain is inflammation and the inflammatory response. Part 1 of 3--a unifying law of pain. Med Hypotheses 69: 70-82.

13. Ahlstedt S (1998) Mediators in Allergy Diagnosis. ACI International 10: 37-44

14. Marshall JS, Waserman S (1995) Mast cells and the nerves--potential interactions in the context of chronic disease. Clin Exp Allergy 25: 102-110.

15. DeLeo JA, Colburn RW (1996) The role of cytokines in nociception and chronic pain. In: Weinstein JN, Gordon SL, Buckwalter JA (eds.). Low back pain: a scientific and clinical overview. American Academy of Orthopaedic Surgeons, Rosemont, IL, USA. Pg no: 163-185.

16. Radhakrishnan V, Henry JL (1995) Electrophysiology of neuropeptides in the sensory spinal cord. Prog Brain Res 104: 175-195.

17. Donkin JJ, Turner RJ, Hassan I, Vink R (2007) Substance $P$ in traumatic brain injury. Prog Brain Res 161: 97-109.

18. Besedovsky HO, del Rey A (1996) Immune-neuro-endocrine interactions: facts and hypotheses. Endocr Rev 17: 64-102.

19. Samad TA, Moore KA, Sapirstein A, Billet S, Allchorne A, et al. (2001) Interleukin-1 beta-mediated induction of Cox-2 in the CNS contributes to inflammatory pain hypersensitivity. Nature 410: 471-475.

20. Wyke B (1982) Receptor systems in lumbosacral tissues in relation to the production of low back pain. In: White AA, Gordon SL (eds.). Symposium on Idiopathic Low Back Pain, Miami, Florida, December, 1980. Mosby, USA.

21. Omoigui $S$ (2007) The biochemical origin of pain: the origin of all pain is inflammation and the inflammatory response. Part 2 of 3 - Inflammatory profile of pain syndromes. Med Hypotheses 69: 1169-1178.

22. Weinstein $\mathrm{J}$ (1991) Neurogenic and nonneurogenic pain and inflammatory mediators. Orthop Clin North Am 22: 235-246.

23. Genuis SJ (2010) Sensitivity-related illness: the escalating pandemic of allergy, food intolerance and chemical sensitivity. Sci Total Environ 408: 60476061. 